\title{
National Educational Technology Standards for Students and Teachers
}

\author{
Chair: Michelle Selinger (UK) \\ Panel: Helen Barrett (US), Bernard Cornu (FR), Pieter Hogenbirk (NL), \\ Robert Munro (UK), Harriet Taylor (US)
}

Keywords: standards, integration of ICT, teacher education, collaborative learning, lifelong
learning

In many countries in which ICT is becoming pervasive in schools, governments are developing a range of similar standards or benchmarks for both students and pre- and in-service teacher training. But are these the appropriate standards? Why should there be standards for the use of this tool? Developments in what it is we should be teaching, and what how knowledge is defined for the information age is also important, but not often recognised in these frameworks.

In addition it is recognised that teacher development in the integration of ICT goes through a number of stages from substitution through transition to transformation, but this is not reflected in the standards frameworks in many countries which assume some level of conformity. Setting levels in standards can provide a framework for both teacher training and for students but can also be an inhibitor. Levels can limit and constrain students and teachers aspirations for their students, and standards are too technical, therefore inhibiting the use of technology as teachers concerns focus on meeting the requirements. The real purpose is lost.

Perhaps we need educational standards rather than specific ICT standards, but which recognise the role ICT can have and lead to a change in the paradigm for learning.

These might include:

- Learning in co-operation 
- Lifelong learning

- Learning in groups

- Learning to learn

- Learning about your own learning styles.

This might make sense if we consider the problems of setting standards; those we set today are not the standards that will be appropriate tomorrow. In addition the ability to reach a set of standards in schools will depend on the four 'pillars' that provide the foundations for effective integration of ICT. These are equipment, connectivity, curriculum and competence. 